\title{
The effects of social context and size of injury on perceptions of a harm-doer and victim
}

\author{
DONELSON R. FORSYTH, EDDIE ALBRITTON, and BARRY R. SCHLENKER \\ University of Florida, Gainesville, Florida $\$ 2611$
}

\begin{abstract}
To examine the effects of the social context of a harm-producing action and the magnitude of harm on evaluations of a harm-doer and victim, 80 female subjects read scenarios that described either a cooperative or competitive interaction in which either mild or severe harm occurred. Ratings of the "aggressor" and "victim" revealed that the harm-doer was evaluated more negatively under competitive rather than cooperative conditions, but was perceived as most aggressive and potent when a severe injury occurred in a cooperative rather than competitive setting. A "just world" effect also occurred in which the victim was derogated when his injury was severe and the context was competitive.
\end{abstract}

Social psychological investigations of aggression have been characterized by a wide and often inconsistent variety of operationalizations of the concept aggression. While this inconsistency makes the interpretations of the research difficult, Tedeschi, Smith, and Brown (1974) propose that examining harm-doing actions from a social influence framework may promote a clearer conceptualization of the nature of aggression. By applying an attributional model to the labeling of acts as aggression, Tedeschi et al. conclude that harm-doing actions will be perceived as aggression only when intentionality is attributed to the actor and the act is considered antinormative. Experimental investigations have supported their contention that behavior must be interpreted within the context in which it occurs, demonstrating that the perception of aggression depends on such variables as the actor's intentions (Bandura, 1973), post-transgression behaviors (Schwartz, Kane, Joseph, \& Tedeschi, Note 1), role (Lincoln \& Levinger, 1972), and the justifiability of the behavior (Rivera \& Tedeschi, 1976; Brown \& Tedeschi, Note 2). These and other relevant studies clearly demonstrate that much of the previous work in aggression generated amphibolic results since the social context of the experimental situation was too often overlooked.

Because the perception of aggression is inextricably linked with attribution of responsibility, factors which affect responsibility attributions will most likely have similar effects on the perception of aggression. For example, several investigations have indicated that the severity of the consequences of some events affects attributions, with the general pattern of results support-

The present study was facilitated by the support of the Organizational Effectiveness Research Program, Office of Naval Research (Code 452), under Contract N00014-75-C-0901, NR 170-797, to the third author. Reprint requests should be sent to Barry R. Schlenker, Department of Psychology, University of Florida, Gainesville, Florida 32611. Marvin E. Shaw sponsors this paper and takes full editorial responsibility for it. ing the conclusion that attribution of responsibility is greater following acts with severe consequences in comparison to acts with mild consequences (e.g., Shaw \& Sulzer, 1964). When applied to the perception of aggression, this finding suggests that an individual who produces severely negative consequences for others may be seen as more aggressive than the person whose behavior produces only mildly negative consequences.

The present investigation attempted to further examine both the effects of social context and outcome severity on the perception of a harm-doer and victim. Subjects were presented with scenario descriptions of a dyadic interaction which ended with an individual (the aggressor) performing a harm-doing action against another (the victim). The social context of the action was manipulated by differentially describing the situation as either cooperative or competitive, and the inflicted injury was described as either severe or mild. Because harm-doing behavior may be perceived as more antinormative in a cooperative setting, it was predicted that the harm-doer would be rated as more aggressive and as possessing more negative traits in the cooperative conditions in comparison to the competitive conditions. Also, it was predicted that producing a severe rather than mild injury would have similar effects on subjects' evaluations and perceptions of an aggressor.

\section{METHOD}

\section{Subjects}

Eighty undergraduate females participated in the experiment in groups of five, with subjects being randomly assigned to one condition in the 2 (cooperative vs. competitive) by 2 (high vs. low injury) factorial design.

\section{Procedure}

Subjects were asked to read a brief scenario describing an interaction between two people, their individual motivations, and the set of circumstances leading to the described actions. In each, a minor disagreement builds up to a confrontation between the two individuals, and culminates in one party (the aggressor) either pushing or tripping the other (the victim). The context of the interactions was manipulated by describing the relation- 
ship between the two interactants as one of cooperation (college roommates or husband and wife) or competition (opposing track team members or business competitors for a contract). The severity of the injury was manipulated by stating that the victim suffered some minor discomfort (twisted ankle) or a major injury that required hospitalization (injured head). In order to increase the generality of results, two different scenarios were employed in each of the experimental conditions. In the cooperative conditions, either a husband and wife or college roommates were having an argument that resulted in one deliberately pushing the other, causing the small vs. large injury. In the competitive conditions, either two opposing track team members or two businessmen were competing to win a race or gain a contract, and one deliberately pushed or tripped the other, causing the small vs. large injury.

\section{Dependent Measures}

After the subjects read the scenario for their assigned condition, they were asked to rate both the aggressor and victim on separate but identical lists of 26 bipolar adjectives in 7-point, semantic differential format.

\section{RESULTS}

In order to extract the major dimensions that describe how subjects viewed the scenario interactants, ratings of the aggressor and victim were separately factor analyzed using principle component solutions and orthogonal varimax rotation. Four factors were retained in subsequent analyses of both the aggressor and victim ratings since additional factors did not significantly add to percentage of variance accounted for nor promote a meaningful interpretation of the data. Standardized factor scores were also generated for each subject, and were then analyzed in a 2 by 2 least squares analysis of variance procedure that corrected for unequal cell sizes (Appelbaum \& Cramer, 1974), followed by simple effects tests when appropriate.

\section{Aggressor Ratings}

The four factors extracted from the aggressor ratings accounted for $63 \%$ of the total variance and included the following dimensions: evaluative (e.g., good-bad, right-wrong, fair-unfair), active-aggressive (e.g., activepassive, aggressive-nonaggressive), potency (e.g., weakstrong, impotent-potent), and competitiveness (e.g., competitive-cooperative, superior-inferior).

Analysis of the standardized factor scores revealed a main effect of context on the Evaluative factor $[F(1,72)=357.14, p<.001]$, with subjects in the competitive conditions rating the aggressor more unfavorably than subjects in the cooperative conditions; means were -.925 and +.867 , respectively. Although no other main effects were obtained on any of the factors, a Context by Degree of Injury interaction was found on both the Active-Aggressive factor $[\mathrm{F}(1,72)=4.52$, $\mathrm{p}<.04]$ and Potency factor $[\mathrm{F}(1,72)=4.15, \mathrm{p}<.04]$. Means are presented in Table 1. Both interactions showed that the context of the interaction had little effect on ratings when the injury was slight, but when a serious injury occurred, the aggressor was rated as more active-aggressive and potent when the context of the
Table 1

Effects and Context and Degree of Injury Ratings of the Aggressor and Victim

\begin{tabular}{|c|c|c|c|c|}
\hline \multirow[b]{2}{*}{ Dimension } & \multicolumn{2}{|c|}{$\begin{array}{c}\text { Competitive } \\
\text { Condition }\end{array}$} & \multicolumn{2}{|c|}{$\begin{array}{c}\text { Cooperative } \\
\text { Condition }\end{array}$} \\
\hline & $\begin{array}{l}\text { High } \\
\text { Injury } \\
(n=16)\end{array}$ & $\begin{array}{c}\text { Low } \\
\text { Injury } \\
(n=23)\end{array}$ & $\begin{array}{l}\text { High } \\
\text { Injury } \\
(n=17)\end{array}$ & $\begin{array}{c}\text { Low } \\
\text { Injury } \\
(n=24)\end{array}$ \\
\hline \multicolumn{5}{|l|}{ Aggressor } \\
\hline $\begin{array}{l}\text { Active-Aggressive } \\
\text { Potency }\end{array}$ & $\begin{array}{l}-.442 \\
-.521\end{array}$ & $\begin{array}{l}+.116 \\
+.196\end{array}$ & $\begin{array}{l}+.347 \\
+.278\end{array}$ & $\begin{array}{l}-.062 \\
-.037\end{array}$ \\
\hline \multicolumn{5}{|l|}{ Victim } \\
\hline Evaluative & -1.041 & -.275 & +.592 & +.539 \\
\hline
\end{tabular}

Note-Cell ns are presented in parentheses. Positive numbers indicate more active-aggressiveness, potency, and positive evaluations.

action was cooperative rather than competitive (ps $<.05)$.

\section{Victim Ratings}

The four factors extracted from the victim ratings accounted for $58 \%$ of the total variance and included the following dimensions; evaluative (e.g., legal-illegal, good-bad, fair-unfair), sociability (e.g., gentle-harsh, sociable-unsociable), active-aggressive (e.g., activepassive, aggressive-nonaggressive), and defensiveness (e.g., defensive-offensive, accidental-purposeful). Significant effects were obtained only on the Evaluative factor, with main effects of both degree of injury and context qualified by an interaction of Injury by Context $[F(1,72)=5.24, p<.03]$. As shown in Table 1 , the victim was rated positively in cooperative contexts irrespective of the degree of injury. However, when the situation was competitive, the victim who was seriously injured was rated more negatively than one who received only minor injuries $(p<.05)$. Overall, the victims in the competitive situation were rated more negatively than victims in a cooperative context ( $\mathrm{ps}<.001)$.

\section{DISCUSSION}

As hypothesized, the harm-doer was perceived as more activeaggressive and potent under cooperative rather than competitive conditions, although this effect occurred only when the consequences involved severe injury. Contrary to predictions, evaluations of the harm-doer did not parallel perceptions of aggression and potency. Regardless of the degree of injury, the harm-doer was rated more negatively in the competitive than cooperative context. The latter finding may be interpreted by focusing on the informational value of the action in the different contexts. Under competitive conditions, an aggressive act may signify greater intentionality to cause major injury-the deliberate expression of antinormative coercion designed to secure a personal goal. Since coercion may seem more likely under these conditions, the aggressor is viewed as less active-aggressive and potent, but is disliked. Under cooperative conditions, which are usually characterized by good member relations and joint action, a harm-producing action undertaken to settle an argument may be seen as less intentional and self-serving, more a matter of everyday "bickering," or the desire to cause only minor injury. The person is viewed as more active-aggressive 
and potent, but is not as disliked. In partial support of this reasoning, a main effect of context was revealed on ratings of the aggressor's intentionality, with subjects perceiving him as more intentional under competitive than cooperative conditions $[F(1,72)=120.35, \mathrm{p}<.001]$.

The victim was rated more positively under cooperative rather than competitive conditions, and this effect was most pronounced when the injury was severe. Subjects derogated the seriously injured victim in the competitive context, apparently justifying the suffering by exaggerating his or her negative characteristics. This "just world" effect (Lerner \& Simmons, 1966), where victims are perceived to deserve what they get, was eliminated in the cooperative context, perhaps because it is more difficult to derogate a member of a cooperative pair. In a competitive situation it is easier to view the victim as suffering because of his or her own selfish, competitive motives, and therefore derogate him or her.

\section{REFERENCE NOTES}

1. Schwartz, G. S., Kane, T. R., Joseph, J. M., \& Tedeschi, J. T. The effects of post-transgression remorse on perceived aggression, attributions of intent, and level of punishment. Mimeographed manuscript. State University of New York at Albany, 1975.

2. Brown, R. C., Jr., \& Tedeschi, J. T. Determinants of perceived aggression. Mimeographed manuscript, State University of New York at Albany, 1973.

\section{REFERENCES}

Appelbaum, M. I., \& Cramer, E. M. Some problems in the nonorthogonal analysis of variance. Psychological Bulletin, 1974, 81, 335-343.

Bandura, A. Aggression: A social learning analysis. Englewood Cliffs, N.J: Prentice-Hall, 1973.

LeRner, M. J., \& Simmons, C. H. Observer's reaction to the "innocent victim": Compassion or rejection? Journal of Personality and Social Psychology, 1966, 4, 203-210.

Lincoln, A., \& Levinger, G. Observers' evaluations of the victim and the attacker in an aggressive incident. Journal of Personality and Social Psychology, 1972, 22, 202-210.

Rivera, A. N., \& Tedeschi, J. T. Competitive behavior and perceived aggression. Perceptual and Motor Skills, 1976, 42, 485-486.

Shaw, M. E., \& Sulzer, J. L. An empirical test of Heider's levels in attribution of responsibility. Journal of Abnormal and Social Psychology, 1964, 69, 39-46.

Tedeschi, J. T., SMIth, R. B., \& Brown, R. C., JR. A reinterpretation of research on aggression. Psychological Bulletin, 1974, 81, 540-563.

(Received for publication August 12, 1976.) 